\title{
EXPERIMENTAL AND NUMERICAL STUDY ON CEMENT PASTE DEGRADATION UNDER EXTERNAL SULFATE ATTACK
}

\author{
XU MA ${ }^{*}$, OĞUZHAN ÇOPUROĞLU ${ }^{*}$, ERIK SCHLANGEN ${ }^{*}$, NINGXU HAN $^{\dagger}$ AND \\ FENG XING ${ }^{\dagger}$ \\ Delft University of Technology \\ Stevinweg 1, 2628 CN Delft, the Netherlands \\ e-mail: X.Ma-1@tudelft.nl; O.Copuroglu@tudelft.nl; Erik.Schlangen@tudelft.nl \\ ${ }^{\dagger}$ Guangdong Province Key Laboratory of Durability for Marine Civil Engineering, Shenzhen University \\ Shenzhen 518060, PR China \\ e-mail: nxhan@szu.edu.cn; xingf@szu.edu.cn
}

Key words: External Sulfate Attack, Expansion, Crystallization Pressure, Lattice Model

\begin{abstract}
External sulfate attack is one of the situations that may cause gradual but severe damage in cementitious materials, which may lead to cracking, increased permeability and strength loss. In this paper, thin-walled hollow cement paste cylinders with a wall thickness of $2.5 \mathrm{~mm}$ were made considering the slow penetration process of sulfate ions under continuous immersion condition. Three types of longitudinal restraints were applied on the hollow cement paste cylinders by means of a spring and steel bars through the specimens in order to facilitate non-, low- and high-restraint conditions. Strain gauges were glued on the steel bars so as to increase the accuracy of the measurements. During the immersion tests, specimen expansion and generated stress were monitored. Additionally, sulfur element mapping was generated by EDS (energy dispersive X-ray spectrometry).

Expansion behaviours of the hollow cement paste cylinders were simulated under the aforementioned restraint conditions which were carried out based on the Delft lattice fracture model. The expansion was assumed to be realized upon formation of ettringite inside the nanopores of the cement hydration products. Local expansion stresses were computed by employing the crystallization pressure theory. A comparison between the simulation and the experimental results showed reasonable correlation and tendency for further exploration of our approach.
\end{abstract}

\section{INTRODUCTION}

External sulfate attack is a progressive durability issue that may cause gradual but severe damage in cementitious materials. Sulfate ions present in seawater, rivers, soils, groundwater, and industrial effluent pose a major threat to the long-term durability of the concrete exposed to these environments.

External sulfate attack in a saturated situation can be defined as the progress of expansive chemical reactions between allochthonous sulfate ions and cement hydration products, which lead to the formation of mainly ettringite and gypsum. The formation will result in a volume increase. The volume increase within cementitious materials can not only reduce the porosity initially but may also cause cracking when the expansion tension exceeds the resistance 
tension, which leads eventually to a strength loss and increased permeability. The damage evolution will affect the durability of the cementitious materials and subsequently the structure [1].

Several theories have been proposed to explain the possible mechanism of expansion, such as topochemical reactions, volume increase, swelling and crystallization pressure. Although the mechanism is still under debate, the crystallization pressure theory has become the most widely cited hypothesis in recent years [2-4].

External sulfate attack under continuous immersion condition is a slow process. Even though the high water/cement ratio and high sodium sulfate concentration are adopted as accelerated methods, it seems that the attack depth is still very small after several months, such as around $3 \mathrm{~mm}$ after 120 days exposure $[3,5]$. Therefore, the sample with a small thickness along the diffusion direction becomes very important for getting the meaningful experimental results which was considered in the present research.

\section{EXPERIMENTAL}

\subsection{Materials and testing procedure}

An ordinary Portland cement (CEM I 42,5 $\mathrm{N})$ with a water/cement ratio of 0.40 was used in this study. PVC moulds with stainless steel rods in the center (Figure 1) were made to obtain the thin-walled hollow cement paste cylinders. During casting of the cement paste mixtures, the moulds were put on a vibration table. After casting, the samples were wrapped with plastic foil together with the moulds for 24 hours. Then the samples were demoulded and cured in saturated limewater at $20{ }^{\circ} \mathrm{C}$ for another 90 days.

After 90 days in saturated limewater, the thin-walled hollow cylinders were cut and polished at both ends to be horizontal with the length of $70 \mathrm{~mm}$ (outer diameter $30 \mathrm{~mm}$, inner diameter $25 \mathrm{~mm}$, wall thickness $2.5 \mathrm{~mm}$ ) [2]. Then three types of longitudinal restraints were applied on the samples with a spring, a thin steel bar (diameter $3 \mathrm{~mm}$ for the middle part) and a thick steel bar (diameter $7 \mathrm{~mm}$ for the middle part) in the middle (Figure 1) to build the non-restraint, low-restraint and highrestraint conditions. In order to ensure a firm contact between the steel disks and samples under low- and high-restraint conditions, 0.7 $\mathrm{N} \cdot \mathrm{m}$ was imposed on the nuts with a precision torque wrench.

Then the samples together with the three types of restraints were immersed in sodium sulfate solutions with the concentrations of 1.5 $\mathrm{g} / \mathrm{L}$ and $30 \mathrm{~g} / \mathrm{L} \mathrm{SO}_{4}{ }^{2-}$ standing for field and accelerated conditions, respectively. For each concentration of sodium sulfate solutions, another 5 samples were also directly immersed to be used for other purposes such as EDS elemental mapping. The tests were carried out in a constant temperature room at around $20{ }^{\circ} \mathrm{C}$. The sulfate solutions were renewed every two weeks.

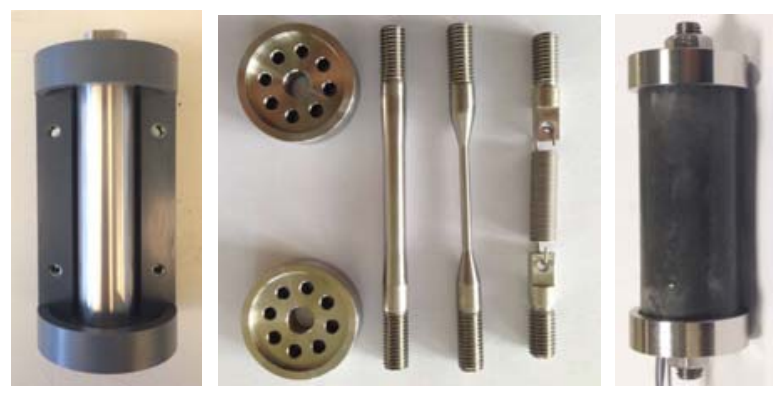

Figure 1: PVC mould and three types of restraints.

Two strain gauges were glued on the opposite sides of the stainless steel bars to increase the accuracy of the measurements. The use of two strain gauges for each steel bar can reduce the influence from bending during the tests. Then a special coating was applied on the surfaces of strain gauges to protect the strain gauges when exposed to sulfate solutions. After that, the tensile calibration tests and the torque calibration tests were carried out to obtain the stress-strain curves and the relationship between local strain and total strain of the steel bars. The strain values of strain gauges were measured with a CompactDAQ system connected to a computer.

During the immersion tests, the free expansion and the local restrained expansion which is from strain gauges were measured. 
The generated stress and the total restrained expansion were calculated. The attack depth was also investigated by EDS elemental mapping.

\subsection{The generated stress}

Firstly, the steel bars without samples were immersed in $1.5 \mathrm{~g} / \mathrm{L}$ and $30 \mathrm{~g} / \mathrm{L}$ sodium sulfate solutions respectively for 5 days. It can be found that all the strain values from the strain gauges remained fairly constant which proves that the sulfate solutions will not influence the strain value. Then the samples were immersed in sulfate solutions together with steel bars.

The steel bars were calibrated through tensile tests and the stress-strain curves were acquired where the strain means the strain value from the strain gauges. During the immersion tests, the continuous strain values were recorded through the computer. Based on the stress-strain curves, the generated stress caused by external sulfate attack was calculated. The results of 35 days immersion tests under low-restraint condition can be seen in Figure 2, where the stress means the expansion stress of the samples.

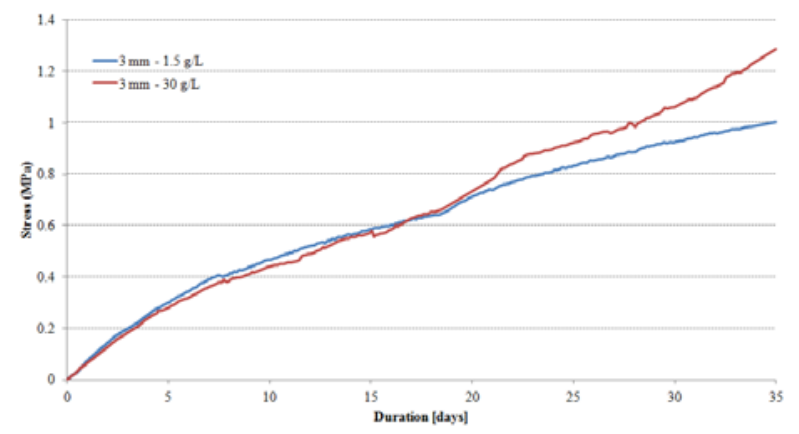

Figure 2: Generated stress under low-restraint.

\subsection{The free and restrained expansions}

The free expansion which means a spring is in the middle of the samples was measured at 14 days, 28 days and 35 days using a dial indicator gauge.

The local restrained expansion which means the strain gauge expansion was obtained through the computer. While the total restrained expansion which means the expansion of the whole steel bar cannot be acquired directly. Because the cross-sectional areas of one steel bar are different along the longitudinal direction, the strain is different for different parts of one steel bar when same load is applied along the longitudinal direction. The strain gauges were glued in the middle part of the steel bars with the smallest diameter. Therefore, in order to get the total restrained expansion, the torque calibration tests were carried out before the immersion tests.

A certain torque was increased in each step with a torque wrench, and the strain from the strain gauges was read from the computer. The length change of the steel bars was measured using a dial indicator gage and then the total strain was calculated. The linear relationship between the local strain from the strain gauges and the total strain of the steel bars can be expressed as equation (1), and the coefficients $\left(\mathrm{k}_{1}\right)$ were calculated as shown in Table 1.

$$
\varepsilon=k_{1} \cdot \varepsilon_{1}
$$

where $\varepsilon_{1}$ is the strain value from strain gauges, and $\varepsilon$ is the total strain of steel bars.

Table 1: The calculated results of $\mathrm{k}_{1}$

\begin{tabular}{ccc}
\hline Thin steel bar $(3 \mathrm{~mm})$ & $1.5 \mathrm{~g} / \mathrm{L}$ & $30 \mathrm{~g} / \mathrm{L}$ \\
\hline $\mathrm{k}_{1}$ & 0.4092 & 0.4290 \\
\hline Thick steel bar $(7 \mathrm{~mm})$ & $1.5 \mathrm{~g} / \mathrm{L}$ & $30 \mathrm{~g} / \mathrm{L}$ \\
\hline $\mathrm{k}_{1}$ & 0.6210 & 0.6989 \\
\hline
\end{tabular}

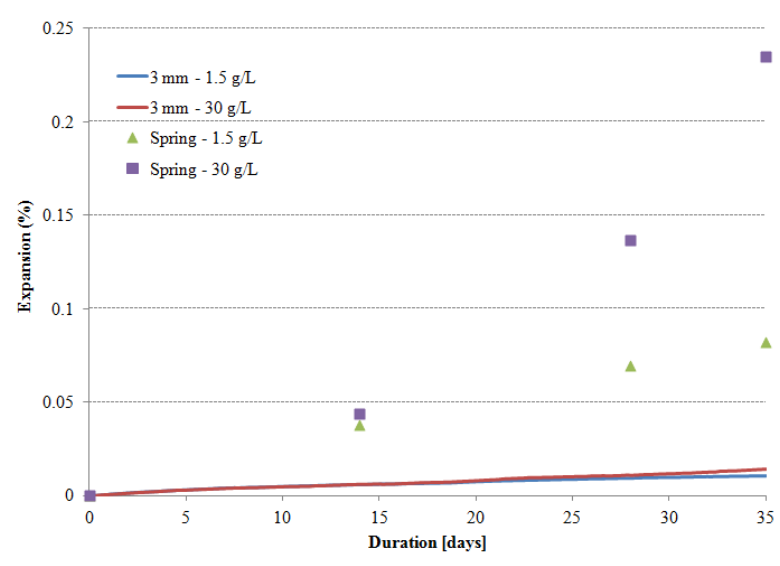

Figure 3: Expansion under two types of restraints.

The total restrained expansion was calculated based on equation (1) and the strain value from strain gauges. All the results of free expansion and low restrained expansion in 1.5 $\mathrm{g} / \mathrm{L}$ and $30 \mathrm{~g} / \mathrm{L}$ sodium sulfate solutions can be 
seen in Figure 3. Figure 4 shows the detailed results under low-restraint condition. The expansion in the curves is expressed as the increased length of the sample divided by the original length of the sample which is $70 \mathrm{~mm}$.

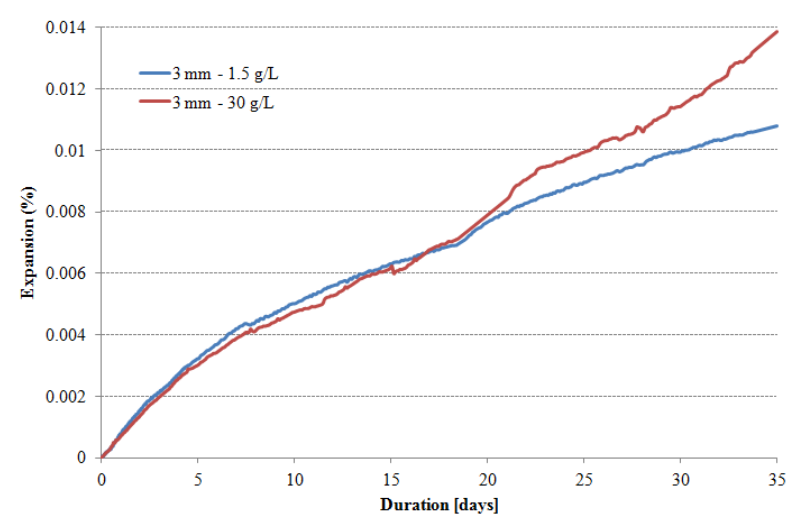

Figure 4: Expansion under low-restraint.

\subsection{Sulfur mapping results}

After immersion in sodium sulfate solutions for 21 days, some of the cement paste samples were taken out and examined by SEM using backscattered electron detector and EDS X-ray mapping analysis. The elemental mappings were obtained at low magnification level $(\times 100)$ which cover an area of $1264 \times 948 \mu \mathrm{m}^{2}$ with the resolution of $256 \times 192$ pixels. The wall thickness of the samples is $2.5 \mathrm{~mm}$ and both of the wall surfaces were exposed to sulfate solutions. Therefore, the length of 1264 $\mu \mathrm{m}$ along the attack direction was considered sufficient for the analysis.

For each sample, in order to make the results more reliable, two areas were selected for analyses which should show similar results. In total two samples were analyzed which were under sulfate attack for 21 days in 1.5 $\mathrm{g} / \mathrm{L}$ and $30 \mathrm{~g} / \mathrm{L}$ solutions respectively. The combined images of BSE image and sulfur mapping in weight percent are shown in Figure 5 and Figure 6 with the red colour representing sulfur element. The left side of the images is the surfaces of the samples which were exposed to sulfate solutions, therefore the external sulfate ions diffused from left to right. And the whole image is a bit larger than half thickness of the samples. It can be found that sulfur gathered in the hydration products.
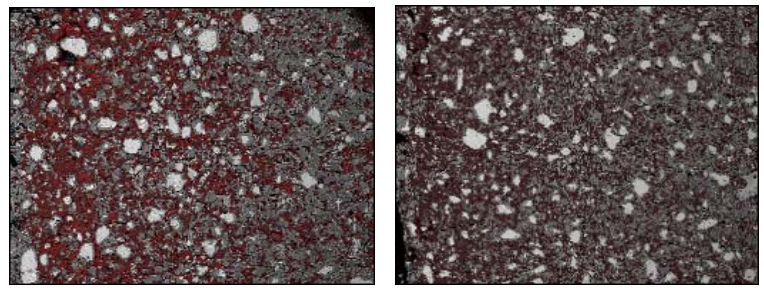

Figure 5: Combined BSE and Sulfur mapping images for $1.5 \mathrm{~g} / \mathrm{L}$. (Left: area 1. Right: area 2.)
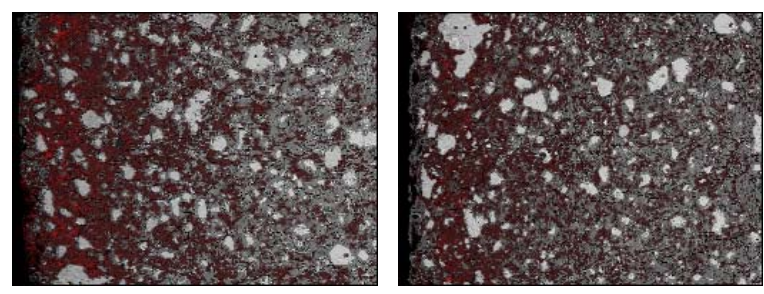

Figure 6: Combined BSE and Sulfur mapping images for $30 \mathrm{~g} / \mathrm{L}$. (Left: area 3. Right: area 4.)

Based on sulfur mappings, the image analyses were completed. Figure 7 shows the average weight percent of sulfur along the sulfate diffusion direction from surface to inside, and the four areas are the same as shown in Figure 5 and Figure 6. It can be found that the attack depth is around $0.8 \mathrm{~mm}$ after 21 days immersion tests.

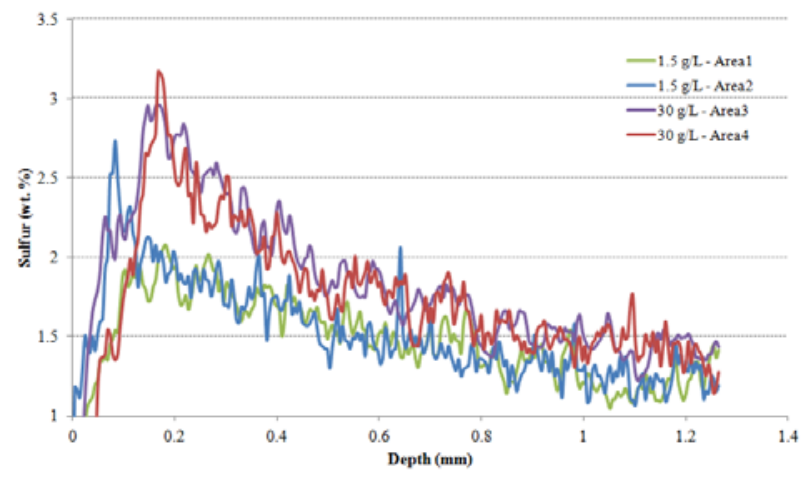

Figure 7:Sulfur distribution along diffusion direction.

\section{SIMULATION}

Expansion behaviours of the hollow cement paste cylinders were simulated under nonrestraint and low-restraint conditions by using the Delft lattice fracture model [6-9]. In the multiscale simulations, the expansion is assumed to be caused by the formation of ettringite in nanopores of the outer product at nanoscale, and the value of the local expansion stress on pore wall is assumed to be based on 
crystallization pressure theory which is related with pore size. The outer product in this paper means the mixtures which mainly include low density C-S-H, calcium hydroxide and monosulfate. Then the total expansion stress at nanoscale was applied on the outer product elements at microscale as the local expansion stress. After that, the calculated total expansion stress at microscale was used as the local expansion stress to all the elements at mesoscale. Finally the free expansion, low restrained expansion and the generated stress under low-restraint condition at mesoscale were obtained.

\subsection{Outer product at nanoscale}

Müllauer, W. [2] got the conclusion through tests that the damage caused by external sulfate attack is due to the formation of ettringite in nanopores $(10-50 \mathrm{~nm})$. Yu, C. [3] provided evidence that expansion is related to the transformation of monosulfate crystals embedded in the C-S-H to ettringite. Through Figure 5 and Figure 6, it also can be found that sulfur gathered in the hydration products. Therefore, for the simulations in this paper, it was assumed that the expansion is caused by the local expansion stress in the nanopores of the outer product.

According to the crystallization pressure theory, the value of the local expansion stress inside the pore is related to the size and shape of the crystals inside the pore which can be expressed as equation (2) [12-14]. Assuming spherical crystals with an interfacial surface energy for ettringite as $0.1 \mathrm{~J} / \mathrm{m}^{2}$ [12-13], crystals with diameter of $10 \mathrm{~nm}$ and $50 \mathrm{~nm}$ are in equilibrium with the maximum stresses of $40 \mathrm{MPa}$ and $8 \mathrm{MPa}$ respectively. The average of the two diameters, diameter of $30 \mathrm{~nm}$ corresponds to a stress of $13.33 \mathrm{MPa}$. This value was assumed to be the local expansion stress in nanopores during the simulations in this paper.

$$
\sigma_{c}=\gamma_{C L} \kappa_{C L}=\frac{\mathrm{R}_{\mathrm{g}} \mathrm{T}}{\mathrm{V}_{\mathrm{c}}} \ln \left(\frac{\mathrm{Q}}{\mathrm{K}}\right)
$$

where $\sigma_{c}$ represents the crystallization pressure exerted on the surrounding pore wall, $\gamma_{C L}$ is the crystal surface energy at the crystal / liquid interface, $\kappa_{C L}$ is the crystal curvature, $\mathrm{R}_{\mathrm{g}}$ is the gas constant, $\mathrm{T}$ is the absolute temperature, $\mathrm{V}_{\mathrm{c}}$ is the crystal molar volume, $\mathrm{Q}$ is the ion activity product and $\mathrm{K}$ is the equilibrium constant.

In order to simplify the simulation as a start, the total expansion stress at nanoscale was assumed to be same as the local expansion stress which is $13.33 \mathrm{MPa}$.

\subsection{Cement paste at microscale}

The microstructure of cement paste at microscale was simulated by HYMOSTRUC $3 \mathrm{D}$ [10-11]. The cement paste is in the shape of a cube with the dimension of $100 \times 100 \times$ $100 \mu^{3}$. The Blaine value of cement is 420 $\mathrm{m}^{2} / \mathrm{kg}$ and the water/cement ratio is 0.40 .

The degree of hydration of the samples before immersed in sulfate solutions was calculated through non-evaporable water test. The result of $74.3 \%$ was obtained. The microstructure from HYMOSTRUC3D with same degree of hydration was chosen (Figure 8). Four different phases can be identified, including unhydrated cement, inner product, outer product and pore.

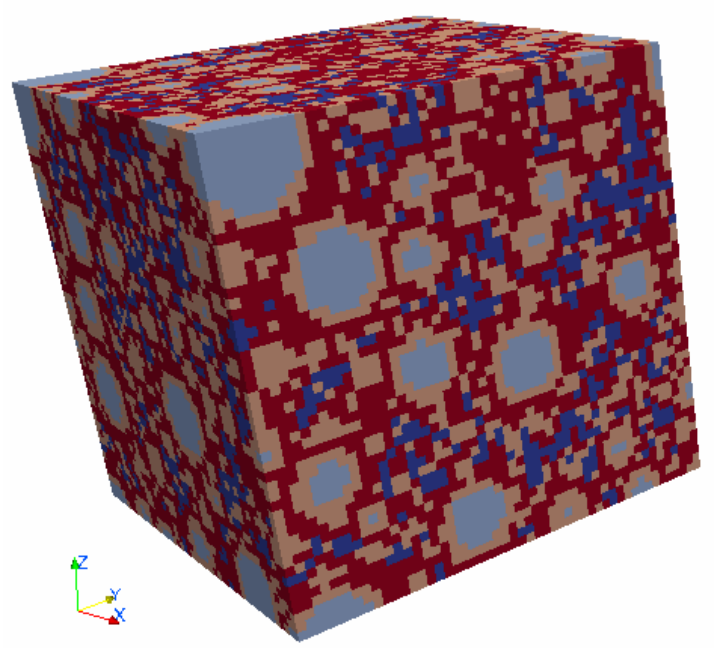

Figure 8: Voxel-based image of the cube.

(Gray = unhydrated cement, pink = inner product, red $=$ outer product, blue $=$ pore)

The assumed local mechanical properties of the solid phases of cement paste at microscale are based on nanoindentation experiment from Hughes, J. J. [15] and 
summarized in Table 2. The tensile strength was assumed to be 85 times lower than the hardness (the ratio between tensile strength and hardness can vary from 28 to 183 for different types of ceramics [16]).

Table 2: The assumed local mechanical properties

\begin{tabular}{ccc}
\hline Solid phase & $\begin{array}{c}\text { Young's modulus } \\
\mathrm{E}(\mathrm{GPa})\end{array}$ & $\begin{array}{c}\text { Tensile strength } \\
\mathrm{f}_{\mathrm{t}}(\mathrm{MPa})\end{array}$ \\
\hline $\begin{array}{c}\text { Unhydrated } \\
\text { cement }\end{array}$ & 45.32 & 32.35 \\
\hline $\begin{array}{c}\text { Inner } \\
\text { product }\end{array}$ & 22.97 & 10.35 \\
\hline $\begin{array}{c}\text { Outer } \\
\text { product }\end{array}$ & 25.74 & 10.35 \\
\hline
\end{tabular}

The vertical displacements of all the nodes at the bottom surface and top surface were prescribed to be 0 . One node at the bottom surface was fixed completely. Then the local expansion stress of $13.33 \mathrm{MPa}$ which was the total expansion stress at nanoscale was applied on all the outer product elements. The simulation was performed with the Delft lattice fracture model. The calculated total expansion stress at the top and bottom is 4.24 MPa.

A uniaxial tensile simulation was carried out in the z-direction for the microstructure in Figure 8 with the mechanical properties in Table 2. The Young's modulus of $17.25 \mathrm{GPa}$ and tensile strength of $3.12 \mathrm{MPa}$ for the whole cement paste cube were obtained.

\subsection{Cement paste at mesoscale}

The hollow cylinder was built with outer diameter of $30 \mathrm{~mm}$, inner diameter of $25 \mathrm{~mm}$ and length of $35 \mathrm{~mm}$ which is half the length of the real sample.

For the non-restraint condition, there is only one solid phase in the structure which is cement paste. All the elements had the same mechanical properties which were from the uniaxial tensile simulation at microscale and shown in Table 3. The vertical displacements of all the nodes at the top surface were prescribed to be 0 . One node at the top surface was fixed completely.

For the low-restraint condition, another solid phase which is the steel bar was added to the bottom of the structure to simulate the restraint caused by the $3 \mathrm{~mm}$ steel bar. As shown in Figure 9, the part with blue color is the solid phase of steel bar, and grey color represents the cement paste. The total crosssectional area of steel bar elements in simulation was calculated based on the equivalent cross-sectional area and the length of the $3 \mathrm{~mm}$ steel bar. The local mechanical properties used in the simulation at mesoscale are shown in Table 3. All the six degrees of freedom of the nodes at the bottom surface were restricted to be 0 . While for all the nodes at the top surface, only vertical displacements were prescribed to be 0 .

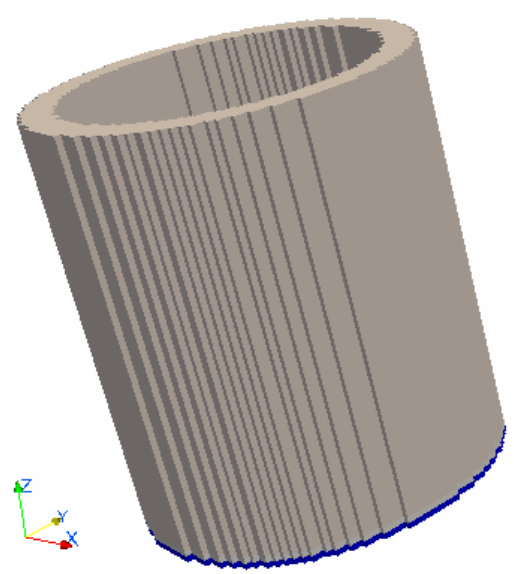

Figure 9: Voxel-based image of the hollow cylinder.

Table 3: The local mechanical properties at mesoscale

\begin{tabular}{ccc}
\hline Solid phase & $\begin{array}{c}\text { Young's modulus } \\
\mathrm{E}(\mathrm{GPa})\end{array}$ & $\begin{array}{c}\text { Tensile strength } \\
\mathrm{f}_{\mathrm{t}}(\mathrm{MPa})\end{array}$ \\
\hline Cement paste & 17.25 & 3.12 \\
\hline Steel bar & 193 & 600 \\
\hline
\end{tabular}

The situation that external sulfate has reached the inside of sample for a long time and sulfur distribution has become uniform was simulated. Note that this situation was not reached yet in the experiments. In the experiments after 21 days exposure a sulfur gradient was present in the samples, which might even cause higher expansions and stresses. In the simulated case, all the cement paste elements burdened the same local expansion stress of $4.24 \mathrm{MPa}$ which is the total expansion stress at microscale. Furthermore, 
another three simulations were also carried out with local expansion stress of $8.48 \mathrm{MPa}, 12.72$ $\mathrm{MPa}$ and $16.96 \mathrm{MPa}$ imposed on all the cement paste elements respectively. The simulation results of non-restraint condition and low-restraint condition ( $3 \mathrm{~mm}$ steel bar) are shown in Table 4 and Table 5 respectively. The expansion shown in the table was calculated based on the increased length in $\mathrm{z}-$ direction divided by the original model length which is $35 \mathrm{~mm}$.

Table 4: Results of non-restraint condition

\begin{tabular}{ccc}
\hline $\begin{array}{c}\text { Imposed local } \\
\text { stress (MPa) }\end{array}$ & $\begin{array}{c}\text { Number of } \\
\text { damaged elements }\end{array}$ & $\begin{array}{c}\text { Expansion } \\
(\%)\end{array}$ \\
\hline 4.24 & 0 & 0.02387 \\
\hline 8.48 & 0 & 0.04774 \\
\hline 12.72 & 0 & 0.07162 \\
\hline 16.96 & 1 & 0.09549 \\
\hline
\end{tabular}

Table 5: Results of low-restraint condition

\begin{tabular}{cccc}
\hline $\begin{array}{c}\text { Imposed } \\
\text { local stress } \\
(\mathrm{MPa})\end{array}$ & $\begin{array}{c}\text { Number of } \\
\text { damaged } \\
\text { elements }\end{array}$ & $\begin{array}{c}\text { Expansion } \\
(\%)\end{array}$ & $\begin{array}{c}\text { Generated } \\
\text { stress } \\
(\mathrm{MPa})\end{array}$ \\
\hline 4.24 & 0 & 0.00386 & 2.99 \\
\hline 8.48 & 2 & 0.00773 & 5.98 \\
\hline 12.72 & 22 & 0.01159 & 8.97 \\
\hline 16.96 & 623 & 0.01543 & 11.94 \\
\hline
\end{tabular}

Table 6: Comparison between simulation and experimental results

\begin{tabular}{cccc}
\hline & $\begin{array}{c}\text { Free } \\
\text { expansion } \\
(\%)\end{array}$ & $\begin{array}{c}\text { Low } \\
\text { restrained } \\
\text { expansion } \\
(\%)\end{array}$ & $\begin{array}{c}\text { Generated } \\
\text { stress } \\
(\mathrm{MPa})\end{array}$ \\
\hline Simulation & 0.02387 & 0.00386 & 2.99 \\
\hline $1.5 \mathrm{~g} / \mathrm{L}$ & 0.05339 & 0.00795 & 0.74 \\
\hline $30 \mathrm{~g} / \mathrm{L}$ & 0.09009 & 0.00842 & 0.78 \\
\hline
\end{tabular}

The comparison between simulation and experimental results are shown in table 6 . The simulation results are from the imposed local stress of $4.24 \mathrm{MPa}$. The experimental results are from the samples exposed to sulfate solutions for 21 days, and the free expansion took the linear interpolation between 14 days and 28 days. The results between simulation and experiment showed reasonable correlation and tendency. While it can also be found that the free expansion and low restrained expansion in simulation are smaller than the values from experiment. In the simulation it was assumed that a uniform sulfur distribution is researched, while the experimental results are from the 21 days immersion tests. This has several implications. First, the assumed mechanical properties of the elements could be different from the real case, especially for the Young's modulus and the connected relaxation. Second, the assumed expansion pressure in the nanopores maybe is not accurate. However, the tendency observed in the simulation is reasonable.
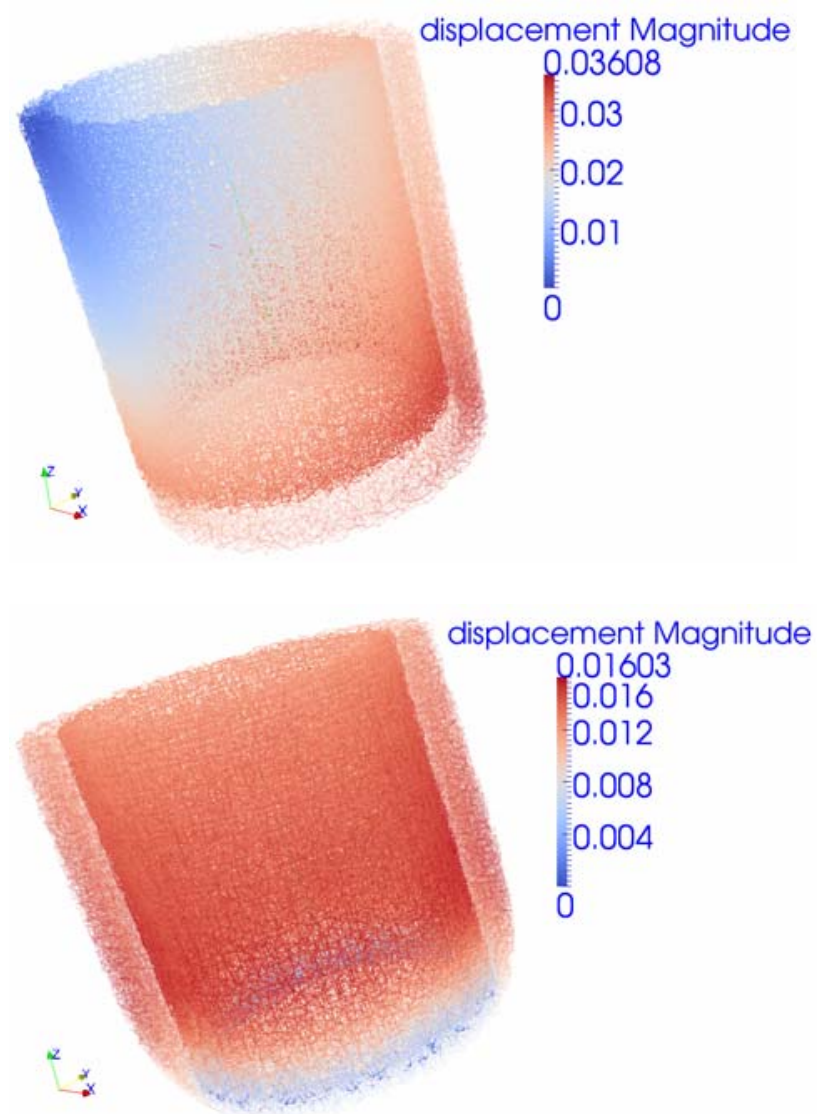

Figure 10: Displacement under non-restraint (above) and low-restraint conditions (below).

Figure 10 shows the comparison for the displacement between non-restraint and lowrestraint conditions when local expansion stress of $16.96 \mathrm{MPa}$ was imposed. Figure 11 shows the crack pattern under low-restraint 
condition when local expansion stress of 16.96 MPa was imposed, while only one element got damaged under non-restraint condition. It can be seen that only distributed micro-cracks are obtained. At later stages of the process and with high restraint conditions, which will be the next step in the project, localized cracks are expected.

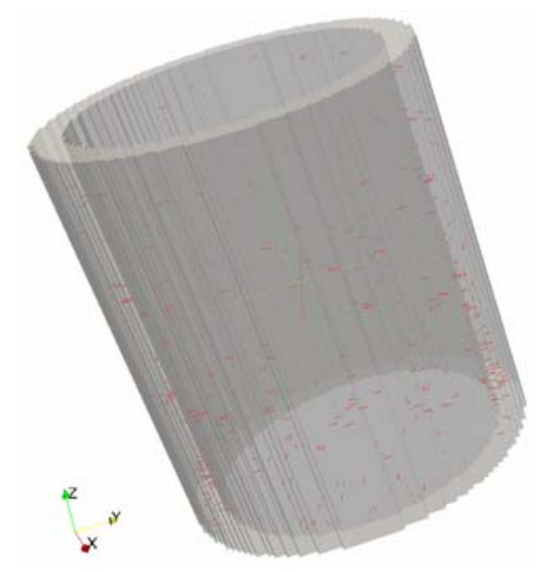

Figure 11: Crack pattern under low-restraint condition.

\section{CONCLUSIONS}

In this paper a research is presented of degradation of cement paste under external sulfate attack.

Cement paste hollow cylinders with a wall thickness of $2.5 \mathrm{~mm}$ were made and three types of longitudinal restraints were applied. In order to increase the accuracy of the measurements, two strain gauges were glued on each steel bar.

The free expansion, low restrained expansion and generated expansion stress under low-restraint condition were measured and calculated during the samples exposed to $1.5 \mathrm{~g} / \mathrm{L}$ and $30 \mathrm{~g} / \mathrm{L}$ sodium sulfate solutions. EDS elemental mappings were acquired for image analyses and the attack depth of around $0.8 \mathrm{~mm}$ after 21 days immersion was found.

A multiscale simulation was accomplished for simulating expansion behaviours of the hollow cement paste cylinders under nonrestraint and low-restraint conditions. The results of the simulation showed reasonable tendency, which form the basis for further research.

\section{ACKNOWLEDGEMENTS}

The scholarship from the Oversea Study Program of Guangzhou Elite Project and the National Basic Research Program (973 Program) of China via Grant No. 2011CB013604 are greatly acknowledged.

\section{REFERENCES}

[1] Skalny, J.P., Marchand, J., and Odler, I. 2002. Sulfate Attack on Concrete, Spon Press, London,.

[2] Müllauer, W., Beddoe, R.E., and Heinz, D. 2013.Sulfate attack expansion mechanisms. Cement and concrete research 52: 208215.

[3] Yu, C., Sun, W., and Scrivener, K. 2013. Mechanism of expansion of mortars immersed in sodium sulfate solutions. Cement and concrete research 43: 105111.

[4] Chabrelie, A. 2010. Mechanisms of degradation of concrete by external sulfate ions under laboratory and field conditions, $\mathrm{PhD}$ thesis, Ecole Polytechnique Federale De Lausanne, Lausanne, Switzerland.

[5] Maltaisa, Y., Samsona, E., and Marchand, J. 2004. Predicting the durability of Portland cement systems in aggressive environments - laboratory validation. Cement and concrete research 34: 15791589.

[6] Çopuroğlu, O. and Schlangen, E. 2008. Modeling of frost salt scaling. Cement and Concrete Research 38: 27-39.

[7] Schlangen, E. 1993. Experimental and numerical analysis of fracture processes in concrete, $\mathrm{PhD}$ Thesis, Delft University of Technology, Delft, the Netherlands.

[8] Qian, Z. 2012. Multiscale modeling of fracture processes in cementitious materials, PhD Thesis, Delft University of Technology, Delft, the Netherlands.

[9] Qian, Z., Schlangen, E., Ye, G., and Van Breugel, K. 2010. Prediction of mechanical properties of cement paste at microscale. Materiales de Construcción 60: 7-18.

[10] Van Breugel, K. 1997. Simulation of 
Hydration and Formation of Structure in Hardening Cement-Based Materials, $\mathrm{PhD}$ Thesis (2nd Edition), Delft University of Technology, Delft, the Netherlands.

[11] Ye, G. 2003. The Microstructure and Permeability of Cementitious Materials, $\mathrm{PhD}$ Thesis, Delft University of Technology, Delft, the Netherlands.

[12] Scherer, G. W. 2004. Stress from crystallization of salt. Cement and Concrete Research 34: 1613-1624.

[13] Steiger, M. 2005. Crystal growth in porous materials - II: Influence of crystal size on the crystallization pressure. Journal of Crystal Growth 282: 470 - 481.

[14] Scherer, G. W. 1999. Crystallization in pores. Cement and Concrete Research 29: 1347-1358.

[15] Hughes, J. J., Trtik, P. 2004. Micromechanical properties of cement paste measured by depth-sensing nanoindentation: a preliminary correlation of physical properties with phase type. Materials Characterization 53: 223- 231.

[16] Zhang, P., Li, S., and Zhang, Z. 2011 General relationship between strength and hardness. Materials Science and Engineering: A 529: 62-73. 